\title{
VIEWPOINT
}

\section{My article has just been rejected!}

\author{
Jean Iwaz \\ Service de Biostatistique-Bioinformatique, Pôle Santé Publique, Hospices Civils de Lyon, Lyon, France; jean.iwaz@chu-lyon.fr; \\ ORCID: 0000-0002-5090-8215
}

DOI: $10.3897 /$ ese.2020.e52497

Unfortunately, articles submitted to journals are rejected more frequently than is desirable. Journals themselves estimate that more than $60 \%$ of submitted articles are rejected without review (for top journals, the figure may even be $80 \%$ ). ${ }^{1-8}$ Thus, whatever an article's content or quality, an outright rejection should be expected right from the time of submission, ${ }^{3}$ and a reaction strategy defined beforehand. Each rejection should be carefully examined and fully understood before attempting any response. Here are some hints for beginners-or for edgy authors.

\section{What does the rejection letter say?}

A rejection letter or message does not have to be a fine piece of rhetoric: it is either a very short and simple phrase or a form letter with cliched expressions to soften the tone, such as 'has been carefully reviewed', 'we are sorry', and 'many excellent papers are rejected'. One may find the letter unintelligible because 1) it does not specify the reason(s) for rejection; 2 ) it is truly unexpected given the manuscript's quality; 3) it consists of vague, conventional phrases, standard formulas, or politically correct jargon to qualify the manuscript ('had a low priority', 'does not add much', 'does not match the journal's style', 'you may send it to ... ', 'we wish you better luck', etc.); or 4) it is read while being particularly nervous. Such a letter, whatever its length, should benefit from a second - and deferred reading if it is to be fully understood, properly interpreted, and adequately acted upon.

\section{How long was the delay between submission and rejection?}

Sometimes, an article is rejected within a week or even 24 hours! In this case, the first person at the journal who has merely read the abstract or the abstract and the conclusions decided right away that the subject of the article is not within the scope of the journal or is not trendy; the article is too long, gives excess of information (for example, too many tables), or is really very badly written. In other cases, the rejection occurs within a month; here, one or at best two people probably read the article and decided it was unsuitable for the journal because of 'borderline' adequacy of the subject, unconvincing research methodology, or overstated conclusions. In yet other cases, the rejection comes more than two months after submission; this usually means that the article was thoroughly read by more than one person and has been rejected most probably based on the decision of the journal's editorial board for several complex reasons.

\section{Was the rejection after a review or without it?}

If the rejection comes without a review, forget the matter for a couple of days and then search for another journal. If the rejection comes after only a cursory review, the comments may be technically fallacious: the sole reader may not have understood the content because of poor presentation or simply because of lack of time or competence. ${ }^{9}$ If you think you have been the victim of an incompetent selector or have received unduly harsh criticism, do not hesitate to complain directly to the Editor-in-chief-unless the latter was himself or herself the critic; in that case, look for another journal without delay, and do the same if you receive no reply to your complaint within a reasonable amount of time (say, two weeks).

At this stage, you and your co-authors may consider submitting the article to another journal in the following cases:

1. the comments of the editor or the co-editor do not sound encouraging;

2. the comments of the two reviewers are too unbalanced or even conflicting;

3. the comments of at least one reviewer are too severe or seem to come from a known or suspected opponent;

4. an additional reviewer has intervened as an arbitrator;

5. two or more major comments seem intractable; or

6. one of the reviewers tries to impose other methods or interpretations requiring a heavy burden of additional work or extending the scope of the manuscript way beyond what the authors intended.

If an outright rejection comes with a detailed review, the review may prove to be of some interest. In that case, wait until you have calmed down (say, a couple of days) before taking further steps but resolve to deal firmly with the rejection as soon as possible.

\section{What next?}

\section{Examine your manuscript}

In the case of a straight rejection without detailed comments, examine your manuscript and check the following issues before accusing the journal's staff of unfair treatment. Is the subject really consistent with the journal's aims and scope? Does the manuscript deal with a single problem? Is your objective accurately stated? Is the Introduction logically progressive? Are the Methods appropriate to the objective? ${ }^{10}$ Are the Results important and credible? ${ }^{11}$ Is the Discussion 'rich'? Are the Conclusions clear, honest, and consistent with 
the objective? Is the Abstract readable and representative of the manuscript? Is the writing clear? Is the manuscript written in reasonably good English? ${ }^{10,11}$ This is a rather long list but such a systematic evaluation will help you understand the journal's comments and revise the manuscript (for more exhaustive and structured lists of flaws, see ${ }^{12-20}$ and the EASE Guidelines for Authors and Translators of Scientific Articles to be Published in English). ${ }^{21}$ Concurrently, share the review or the rejection letter with your co-authors (if the journal has not already done so) and tell them they will be involved in the revision process.

\section{Examine the content of the rejection letter}

Examine the review anew, more thoroughly this time, to sort out the comments. These may be already sorted as 'major' and 'minor' but you may need to sort them using other criteria including the following: 1) essential comments from which you may really benefit because they help you to fill the gaps, remove imperfections, or improve the presentation of the manuscript; 2) comments directed to specific co-authors according to their area of expertise; 3 ) comments that require additional analyses or a non-negligible amount of time and work; and 4) comments that call for additions to text. You may use different colours to highlight each category (or use the 'Comments' feature in 'Track Changes' if you are using Microsoft Word) to focus on various types of revision needed or to assign specific comments to specific co-authors.

\section{Discuss with the co-authors}

Now that you have probably assigned to each co-author the comments related to his or her specific area of expertise, send the highlighted copies or the files with track changes to the co-authors, requesting them to respond. This may take some time because the co-authors may be as disheartened as you, the corresponding author. However, it would be wise to limit this time to no more than a couple of weeks before you begin the process of revising the article.

\section{Distribute the tasks}

Analyse all the responses received from your co-authors and try to arrive at a consensus on each point. Now, redefine or rewrite these points precisely and assign each specific point to a specific co-author. Send this 'final response plan' to the co-authors and set a reasonable common deadline to all depending on the overall workload.

\section{Collect the answers}

Remind your co-authors of the deadline in time and do your best to collect all the responses within a week or two. Be patient: some are always late; be persistent: some are frequent procrastinators. Once all the responses are in, check that they are adequate and do not hesitate to ask for further details or explanations.

\section{Draft the answers}

Now that you have understood all the responses, spend enough time to write them in the same style as that of the original manuscript and find within the manuscript a place for each block of additional text (or table or figure, as the case may be). Make each addition stand out (underline, highlight, or use track changes). Read all revised paragraphs again and then the entire revised manuscript to check for consistency, readability, and compliance with the word limits prescribed by the journal.

\section{Circulate the revised draft}

Send the revised version of the manuscript to all co-authors to check whether they agree with the way you have presented their additions and with the overall presentation. Usually, this does not require much time and should be over within a week or so.

\section{Collect the comments}

Given the efforts already made, the virtually final version should elicit only a few comments from the co-authors, if at all. Act on those comments. Most often, this version does not have to make another round for checks by the co-authors. However, ensure that you fully understand the earlier comments by the co-authors because unsatisfactory corrections may be taken badly and become a source of misunderstanding and disputes.

\section{Finalize the formatting}

The final version may not be yet ready for submission to another journal: you need to format the whole manuscript for the new journal in accordance with its style and instructions to authors. This may require rewriting the Abstract, shortening the text, rewriting parts of Methods or Discussion, adding new sections ('Summary', 'At a glance,' 'Highlights', etc.), or reformatting and reorganizing the references. This may be time-consuming, and the manuscript might require the approval of co-authors, but such revision and reshaping are essential to ensure that your manuscript does not look like it has been 'hastily recycled.'

\section{Before I forget ...}

Keep in mind that the same process might need to be carried out all over again in the case of a second rejection-and good luck!

\section{Competing interests}

The author declares having no financial or non-financial conflicts of interests in relation with this publication. He has no relationships with editorial associations, commercial editing companies, or other organizations that might have an interest in the submission of this viewpoint.

\section{References}

1 Scholarly Publishing Resources for Faculty: Cabell's (Journal Acceptance Rate). Available at: https://liu.cwp.libguides.com/c. php?g=45770\&p=3161505 (last accessed 12 August 2020).

2 Nature. Editorial criteria and processes. Available at: https://www.nature. com/nature/for-authors/editorial-criteria-and-processes (last accessed 12 August 2020).

3 BMJ. Guidance for authors. Available at: https://www.bmj.com/sites/default/ files/attachments/resources/2018/05/BMJ-InstructionsForAuthors-2018. pdf. Page 1 (last accessed 12 August 2020).

4 The Lancet. Information for authors. Available at: https://www.thelancet. $\mathrm{com} / \mathrm{pb} /$ assets/raw/Lancet/authors/lancet-information-for-authors.pdf. Page 8 (last accessed 12 August 2020).

5 Garfield E, Cronin B, Barsky Atkins H (eds). The web of knowledge: A festschrift in honor of Eugene Garfield. Medford, New Jersey: Information Today Inc. 2000: 130.

6 Peat J, Elliott E, Baur L, Keena V. Scientific writing: easy when you know how. London: BMJ Books, 2002: 18 and 130. 
7 Chambliss DF, Schutt RK. Making sense of the social world: methods of investigation. 2nd edition. Newbury Park, California: Pine Forge Press and London: Sage. 2006: 264

8 Denial A. What are the characteristics of a manuscript acceptable for publication? Optometric Education. 2014; 39(3): 98-99. Available at: https://journal.opted.org/articles/Volume39_Number3_Summer2014Editorial.pdf (last accessed 12 August 2020).

9 Fathelrahman AI. Rejection of good manuscripts: possible reasons, consequences and solutions. Journal of Clinical Research \& Bioethics. 2015; 6(1): 1000204. Available at: https://doi.org/10.4172/2155-9627.1000204 (last accessed 12 August 2020).

10 Turcotte C, Drolet P, Girard M. Study design, originality and overall consistency influence acceptance or rejection of manuscripts submitted to the Journal. Canadian Journal of Anaesthesia. 2004; 51(6): 549-556. Available at: https://doi.org/10.1007/BF03018396 (last accessed 12 August 2020).

11 Wyness T, McGhee CN, Patel DV. Manuscript rejection in ophthalmology and visual science journals: identifying and avoiding the common pitfalls. Clinical \& Experimental Ophthalmology. 2009; 37(9): 864-867. Available at: https://doi.org/10.1111/j.1442-9071.2009.02190.x (last accessed 12 August 2020).

12 Ehara S, Takahashi K. Reasons for rejection of manuscripts submitted to AJR by international authors. American Journal of Roentgenology. 2007; 188(2): W113-W116. Available at: https://doi.org/10.2214/AJR.06.0448 (last accessed 12 August 2020)

13 Smith MU, Wandersee JH, Cummins CL. What's wrong with this manuscript? An analysis of the reasons for rejection given by Journal of Research in Science Teaching reviewers. Journal of Research in Science Teaching. 1993; 30(2): 209-211. Available at: https://doi.org/10.1002/ tea.3660300207 (last accessed 12 August 2020).
14 Byrne DW. Common reasons for rejecting manuscripts at medical journals: a survey of editors and peer reviewers. Science Editor. 2000; 23(2): 39-44. Available at: https://www.councilscienceeditors.org/ wp-content/uploads/v23n2p039-044.pdf (last accessed 12 August 2020).

15 Bordage G. Reasons reviewers reject and accept manuscripts: the strengths and weaknesses in medical education reports. Academic Medicine. 2001; 76(9): 889-896. Available at: https://doi.org/10.1097/00001888200109000-00010 (last accessed 12 August 2020).

16 Pierson DJ. The top 10 reasons why manuscripts are not accepted for publication. Respiratory Care. 2004; 49(10): 1246-1252. Available at: http://www.rcjournal.com/contents/10.04/10.04.1246.pdf (last accessed 12 August 2020).

17 Sullivan EJ. Top 10 reasons a manuscript is rejected. Journal of Professional Nursing. 2002; 18(1): 1-2. Available at https://doi.org/10.1053/ jpnu.2002.30890 (last accessed 12 August 2020).

18 Ali J. Manuscript rejection: causes and remedies. Journal of Young Pharmacists. 2010; 2(1): 3-6. Available at: https://doi.org/10.4103/09751483.62205 (last accessed 12 August 2020).

19 Ezeala CC, Nweke IN, Ezeala MO. Common errors in manuscripts submitted to medical science journals. Annals of Medical and Health Sciences Research. 2013; 3(3): 376-379. Available at: https://doi. org/10.4103/2141-9248.117957 (last accessed 12 August 2020).

20 Adhikari K, Kumar A. From dismissal to triumph in scientific publication. Journal of Universal College of Medical Sciences. 2019; 7(2): 78-81. Available at: https://doi.org/10.3126/jucms.v7i2.27145 (last accessed 12 August 2020).

21 [EASE] European Association of Science Editors. 2018. EASE Guidelines for Authors and Translators of Scientific Articles to be Published in English. European Science Editing 2018; 44(4):e1-e16. Available at: https:// doi.org/10.20316/ESE.2018.44.e1 (last accessed 12 August 2020). 